\title{
Synthesis of the Trans-Syn-Trans Perhydrobenzo[f]chromene Ring System
}

\author{
Amjad Ayad Qatran Al-Khdhairawi, ${ }^{a}{ }^{\text {* }}$ Syahrul Imran, ${ }^{\mathrm{b}}$ Nurhuda Manshoor, ${ }^{\mathrm{b}}$ Geoffrey A. \\ Cordell, ${ }^{\mathrm{b}, \mathrm{c}}$ Narendra Babu Shivanagere Nagojappa, ${ }^{\mathrm{a}}$ Jean-Frédéric F. Weber ${ }^{\mathrm{b}, \mathrm{d}}$
}

\author{
${ }^{a}$ School of Pharmacy, Faculty of Health \& Medical Sciences, \\ Taylor's University Lakeside Campus, 47500 Subang Jaya, Selangor, Malaysia \\ ${ }^{b}$ Atta-ur-Rahman Institute for Natural Product Discovery (AuRIns), \\ Universiti Teknologi MARA (UiTM) Selangor Branch, 42300 Bandar Puncak Alam, \\ Selangor, Malaysia \\ 'Natural Products Inc., Evanston, IL 60202, USA and Department of Pharmaceutics, College of Pharmacy, \\ University of Florida, FL, 32610, USA \\ ${ }^{d}$ Current address: Laboratoire de Pharmacognosie, UFR Sciences Pharmaceutiques, \\ Université de Bordeaux, 33076 Bordeaux cedex, France
}

\begin{abstract}
A stereoselective synthesis of the trans-syn-trans perhydrobenzo[f]chromene skeleton is presented. The target compound $\mathbf{3}$ was achieved in six steps starting from the $(S)-(+)$-Wieland-Miescher ketone. Key steps include the sp $^{2}$ alkylation at the $\alpha$-carbon of an unsaturated ketone, Birch-type reductive alkylation, and an acid-catalyzed cyclization.
\end{abstract}

Keywords: Meroterpenoids, regioselective alkylation, stereochemistry, fungal natural products

\section{Introduction}

Previous investigations in this laboratory into the chemistry of endophytic fungi led to the isolation and structure reassignment of the asperginols, a rare group of fungal natural products (1-2) (Figure 1) and the first meroditerpenes to possess a trans-syn-trans stereochemical arrangement. ${ }^{1}$ The tricyclic diterpene core of the asperginols possesses the usual two trans ring junctions, with the unusual

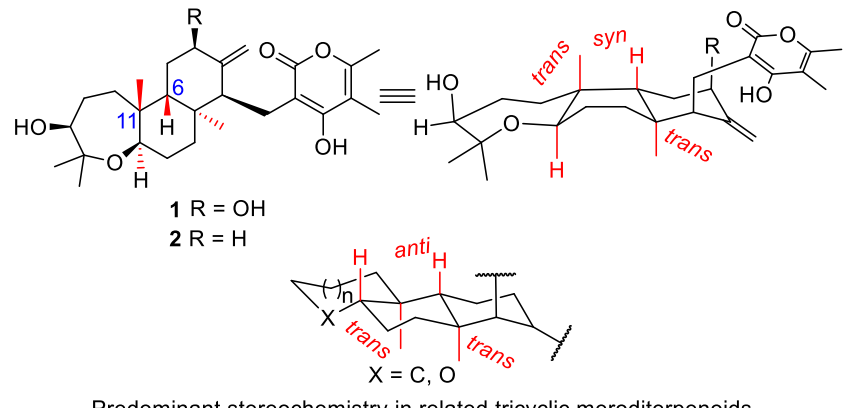

Predominant stereochemistry in related tricyclic meroditerpenoids

Figure 1. Structures of the asperginols and comparison with related natural products. 6,11-syn arrangement. This stereochemistry forces ring B in this tricyclic system to adopt an unfavorable boat conformation. The stereochemistry in all other known tricyclic meroterpenoids is trans-anti-trans, allowing a more thermodynamically favorable chair conformation for ring B. ${ }^{2,3}$

Recently, Baran and colleagues introduced a concise synthetic approach towards the diterpene pyrone subfamily of meroterpenoids, which relied on a biomimetic cyclization. ${ }^{4}$ Other groups have achieved the synthesis of various meroterpenoids through biomimetic cyclization of linear intermediates. ${ }^{5,6}$ However, the thermodynamically unfavorable nature of the trans-syn-trans stereochemistry of asperginols makes such attractive synthetic approaches inapplicable.

In this study, the formation of such trans-syn-trans stereochemistry was investigated by synthesizing the model compound 3 possessing a 6/6/6 tricyclic system. Its synthesis was hypothesized to be more feasible than the 7/6/6 skeleton of the asperginols. The target alcohol $\mathbf{3}$ was expected to be accessible via a late-stage, acid-catalyzed cyclization of

\footnotetext{
*Corresponding author. E-mail address: amjad.khdhairawi@gmail.com (A. A. Q. Al-Khdhairawi).
} 
epoxy alcohol 4, which in turn was anticipated to be obtained from the functionalized ketone $\mathbf{5}$ (Scheme 1). The 4a,5-syn relationship in compound $\mathbf{5}$ was envisioned to be achieved via the kinetic reductive alkylation of enone $\mathbf{6}$ under Birch conditions. The enone $\mathbf{6}$ can be obtained from WielandMiescher ketone (WMK, 7), following ketalization and direct alkylation with homoprenyl bromide $\mathbf{1 3}$.

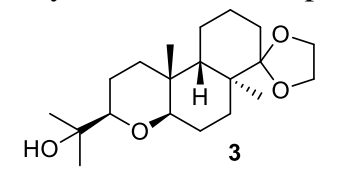<smiles>C=CC</smiles>

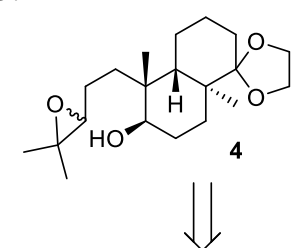<smiles>[3H]C12CCC(=O)C=C1CCCC2=O</smiles><smiles>C=CCCC12CCC3(CCC(=O)C(=O)CCC13)OCCO2</smiles>

Scheme 1. Retrosynthetic analysis of model compound 3.

\section{Results and Discussion}

The synthesis of enantiopure WMK (7) is well documented. ${ }^{7}$ Usually, it is achieved in two steps starting from 2-methyl-1,3-cyclohexanedione 8, and methyl vinyl ketone. However, due to logistical difficulties, methyl vinyl ketone could not be acquired, and the alternative synthon 9 was utilized (Scheme 2). The use of 4-(diethylamino)butan2-one 9 is established for the formation of WMK in one step with a yield of $40-50 \%$ through a Robinson annulation reaction that affords a racemic product. ${ }^{8}$ The conditions for the reaction between $\mathbf{9}$ and $\mathbf{8}$ were modified to stop at the triketone 10, which was then cyclized enantioselectively, using L-proline as a catalyst, to give the desired $(S)-(+)-$ WMK 7, $\left([\alpha]_{D}^{25}+92\right.$, c $\left.0.25, \mathrm{CHCl}_{3}\right)$. The ketal 11 was prepared in high yield following a known procedure by reacting 7 with one equivalent of $p$-toluenesulfonic acid and ethylene glycol at room temperature in the presence of molecular sieves. ${ }^{9}$ Homoprenyl bromide (13) was synthesized from $\gamma$-butyrolactone $\mathbf{1 2}$ following a slightly modified known procedure (Scheme 3 ). ${ }^{10}$

The regioselective alkylation of ketal $\mathbf{1 1}$ at the $\operatorname{sp}^{2} \alpha$ carbon is challenging due to the competing $\mathrm{sp}^{3} \alpha$-carbon.
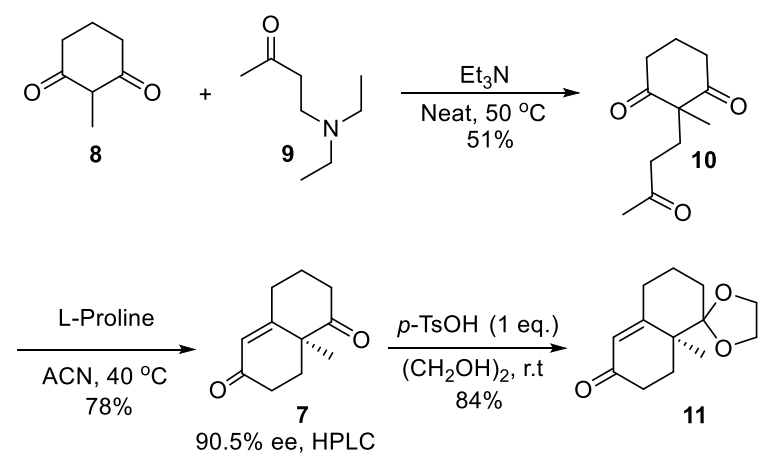

Scheme 2. Synthesis of ketal 11.

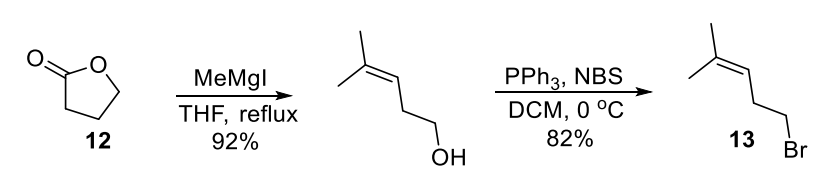

Scheme 3. Synthesis of homoprenyl bromide 13.

Selective alkylation at the $\alpha$-carbon is possible through the formation of the thermodynamic extended enolate of $\mathbf{1 1}$. Early reports of this reaction came from the work of Woodward and colleagues for the C-4 dialkylation of testosterone using potassium tert-butoxide, ${ }^{11}$ and later improved by Atwater to give the monoalkylated C-4 derivatives. ${ }^{12}$ A similar alkylation procedure with much improved yields was reported using sodium hydride and a longer reaction time. ${ }^{13}$ Surprisingly however, for ketal 11, the best results were obtained using a procedure slightly modified from that reported by Atwater employing potassium tert-butoxide and a shorter reaction time. As seen in Table 1, the desired compound $\mathbf{6}$ was achieved as a single product in a relatively good yield (entry 6).

Table 1. Regioselective alkylation of ketal 11.

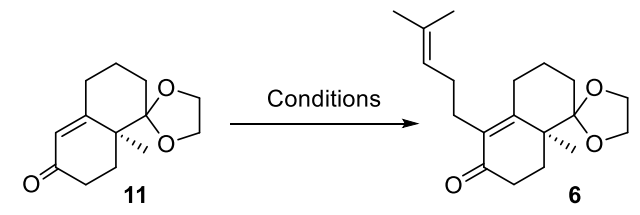

\begin{tabular}{clcc}
\hline Entry & \multicolumn{1}{c}{ Conditions } & Solvent & $\mathbf{6}(\%)$ \\
\hline 1 & $\mathrm{NaH}(1.1$ eq.) at r.t. for $24 \mathrm{hrs}$, then 13 & THF & N/A \\
2 & $\mathrm{NaH}$ (1.1 eq.) at reflux for $24 \mathrm{hrs}$, then 13 & THF & 4 \\
3 & $\mathrm{NaH}\left(1.1\right.$ eq.) at $100^{\circ} \mathrm{C}$ for $24 \mathrm{hrs}$, then 13 & DMSO & 31 \\
4 & $\mathrm{NaH}(1.1$ eq.) at reflux for $24 \mathrm{hrs}$, then 13 & Dioxane & 48 \\
5 & $t$-BuOK (1.1 eq.) at reflux for $14 \mathrm{hrs,} \mathrm{then} \mathrm{13}$ & $t$-BuOH & 50 \\
6 & $t$-BuOK (1.1 eq.) at reflux for $2 \mathrm{hrs,} \mathrm{then} \mathrm{13}$ & $t$-BuOH & 72 \\
\hline
\end{tabular}

With compound $\mathbf{6}$ in hand, attention turned to the installation of a methyl group at the $\beta$ face. This was achieved by subjecting $\mathbf{6}$ to Birch conditions, which gave an enolate that was trapped using methyl iodide. As seen in Scheme 4, methyl iodide approached the enolate from the concave face to avoid the 1,3-diaxial interaction with the C8a-Me. The stereochemical outcome of this type of reductive alkylation is extensively documented ${ }^{14-17}$ and allowed the simultaneous formation of two key stereocenters (C5 and C4a) in $\mathbf{5}$.

To achieve the two trans ring junctions in the final product, the ketone group at C6 must be reduced with a bulky reducing agent to afford the axial alcohol. To our delight, lithium triethylborohydride yielded the desired alcohol $\mathbf{1 4}$ quantitatively, with no trace of the equatorial epimer. The stereochemistry at C11 was not important, and thus the 


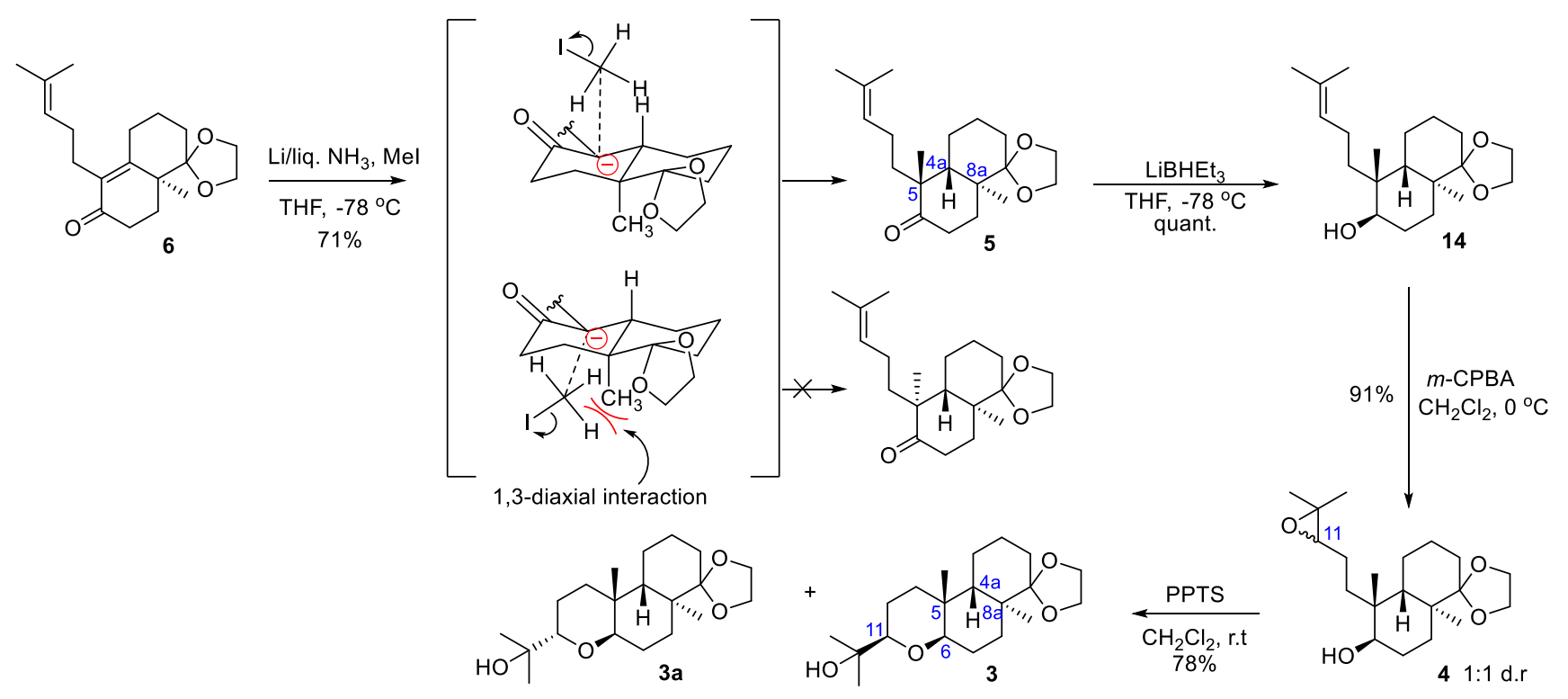

Scheme 4. Synthesis of the trans-syn-trans target compound 3.

convenient $m$-CPBA epoxidation was performed on 14 to provide epoxyalcohol $\mathbf{4}$ as an equal mixture of epimers at C11. The mixture $\mathbf{4}$ was used without purification and biomimetic epoxyalcohol cyclization of $\mathbf{4}$ proceeded smoothly under mildly acidic conditions to give the tricyclic products $\mathbf{3}$ and $\mathbf{3 a}$ in a 1:1 ratio. Distinct chemical shift differences were observed in the proton and carbon NMR of the products. The chemical shifts of C-6 and C-11 in $\mathbf{3}$ were significantly more deshielded ( $\delta$ c 82.1 and 83.5 ) when compared to the values observed in $\mathbf{3 a}$ for the same carbon atoms $\left(\delta_{\mathrm{C}} 75.4\right.$ and 77.4$)$. Conversely, the chemical shifts of $\mathrm{H}-6$ and $\mathrm{H}-11$ in 3 were more shielded $\left(\delta_{\mathrm{H}} 2.82\right.$ and 3.05) than in $\mathbf{3 a}\left(\delta_{\mathrm{H}} 3.20\right.$ and 3.27$)$.

The stereochemistry of compound $\mathbf{3}$ was deduced from its NOESY spectrum, which showed key correlations between C8a-Me $\left(\delta_{\mathrm{H}} 1.01\right)$ and H-6 $\left(\delta_{\mathrm{H}} 2.82\right)$, and H-6 and H-11 $\left(\delta_{\mathrm{H}} 3.05\right)$, highlighting the co-facial relationship of these three hydrogens. The methyl group at C-5 did not show useful NOESY correlations since $\mathrm{H}-4$ a overlapped with other signals in the ${ }^{1} \mathrm{H}$ spectrum of 3 . Similarly, key NOESY correlations determined the stereochemistry of compound $\mathbf{3 a}$, with, for example, the crosspeak between $\mathrm{H}-11\left(\delta_{\mathrm{H}} 3.28\right)$ and $\mathrm{C} 5-\mathrm{Me}\left(\delta_{\mathrm{H}} 0.88\right)$ indicating that $\mathrm{H}-11$ was beta-oriented.

\section{Conclusion}

A concise, stereocontrolled synthesis of the perhydrobenzo[f]chromene system possessing a trans-syntrans stereochemistry is described. Although uncommon in nature, this stereochemistry was observed in a rare group of fungal natural products, the asperginols. This synthetic pathway paves the way towards the synthesis of the asperginols. However, a different approach towards the formation of the oxepane ring is required.

\section{Declaration of Competing Interests}

The authors declare that they have no known competing financial interests or personal relationships that could have appeared to influence the work reported in this paper.

\section{Acknowledgements}

This work was supported by Taylor's University Ph.D. Scholarship program, as well as a research grant from the Ministry of Education of Malaysia, FRGS 1/2019/STGD3/UITM/02/6.

\section{Appendix A. Supplementary data}

Supplementary data for this article can be found online at XXXXXXXXXXXXXXXXXXXXXXX

\section{References}

1 Al-Khdhairawi, A. A. Q.; Low, Y. Y.; Manshoor, N.; Aditya, A.; Jelecki, M.; Alshawsh, M. A.; Kamran, S.; Suliman, R. S.; Low, A. L. M.; Shivanagere Nagojappa, N. B; Weber, J.-F. F. J. Nat. Prod. 2020, 83, 3564-3570.

2 Matsuda, Y.; Abe, I. Nat. Prod. Rep., 2016, 33, 26-53.

3 Al-Khdhairawi, A. A. Q.; Cordell, G. A.; Thomas, N. F.; Shivanagere Nagojappa, N. B.; Weber, J.-F. F. Org. Biomol. Chem., 2019, 17, 8943-8957.

4 Merchant, R. R.; Oberg, K. M.; Lin, Y.; Novak, A. J. E.; Felding, J.; Baran, P. S. J. Am. Chem. Soc., 2018, 140, 7462-7465. 
5 Powers, Z.; Scharf, A.; Cheng, A.; Yang, F.; Himmelbauer, M.;

Mitsuhashi, T.; Barra, L.; Taniguchi, Y.; Kikuchi, T.; Fujita, M.; Abe,

I.; Porco, J. A. Angew. Chem., Int. Ed., 2019, 58, 16141-16146.

6 Ma, T. K.; Elliott, D. C.; Reid, S.; White, A. J. P.; Parsons, P. J.;

Barrett, A. G. M. J. Org. Chem., 2018, 83, 13276-13286.

7 Bradshaw, B.; Bonjoch, J. Synlett, 2012, 337-356.

8 Newman, M. S.; Mekler, A. B.; J. Am. Chem. Soc., 1960, 82, 40394041.

9 Ciceri, P.; Demnitz, F. W. J. Tetrahedron Lett., 1997, 38, 389-390.

10 Sarmah, B. K.; Barua, N. C. Tetrahedron, 1993, 49, 2253-2260.

11 Woodward, R. B.; Sondheimer, F.; Taub, D.; Heusler, K.; McLamore W. M. J. Am. Chem. Soc., 1952, 74, 4223-4224.

12 Atwater, N. W. J. Am. Chem. Soc. 1960, 82, 11, 2847-2852

13 Weber, W.; Kraus, W.; Spitzner, D. Chem. Ber., 1980, 113, 385-390.

14 Bruner, S. D.; Radeke, H. S.; Tallarico, J. A.; Snapper, M. L. J. Org. Chem. 1995, 60, 1114-1115.

15 Poigny, S.; Guyot, M.; Samadi, M. J. Org. Chem., 1998, 63, 5890-5894.

16 Ling, T.; Poupon, E.; Rueden, E. J.; Kim, S. H.; Theodorakis, E. A. J. Am. Chem. Soc., 2002, 124, 12261-12267.

17 Hagiwara, H. Nat. Prod. Commun., 2013, 8, 935-948. 